\title{
ANÁLISE DA SEGMENTAÇÃO VENOSA HEPÁTICA ATRAVÉS DE MOLDES DE RESINA
}

\author{
HEPATIC VENOUS SEGMENTATION ANALYSIS BY RESIN CAST
}

\author{
Fernando César Diógenes Filho ${ }^{1}$ \\ Ítalo Martins de Oliveira ${ }^{2}$ \\ Rubens de Weimar Chaves ${ }^{3}$ \\ Luciana Cidrão Frota ${ }^{3}$ \\ Maurício C. G. de Souza Carvalho ${ }^{3}$ \\ Antônio Ribeiro da Silva Filho, TCBC-CE ${ }^{4}$
}

\begin{abstract}
RESUMO: Objetivo: Aferir a independência da segmentação da drenagem venosa hepática, bem como a relação entre seus segmentos. Método: Foram utilizados trinta fígados humanos, analisados cuidadosamente para exclusão de possíveis rompimentos extra e intra-parenquimatosos. Foi injetada uma resina sintética (Resapol T-208) nas veias hepáticas direita, média e esquerda isoladamente, com diferentes cores, para identificação dos segmentos, utilizando-se a técnica de injeção-corrosão. Após a obtenção dos moldes, foi realizada a pesagem e a planimetria destes, em conjunto e separadamente. Resultados: Foi observado que todos os moldes hepáticos apresentaram independência entre seus segmentos e que o segmento direito foi o maior ( $\mathrm{p}=0,005)$. Ao correlacionar o peso do fígado com a proporção entre os segmentos, obteve-se um coeficiente de correlação de 0,023. Conclusões: Os segmentos das veias hepáticas são independentes entre si, ocorrendo preponderância do segmento venoso direito sobre os demais e o aumento do peso do fígado sem patologia corresponde a um aumento proporcional entre os seus segmentos
\end{abstract}

Descritores: Veias hepáticas; Molde por corrosão; Fígado.

\section{INTRODUÇÃO}

A cirurgia hepática teve, nos últimos 50 anos, um grande desenvolvimento. $\mathrm{O}$ tratamento do trauma hepático e dos tumores, primários ou secundários, como também o desenvolvimento e aperfeiçoamento do transplante hepático, tornaram necessário um maior conhecimento da rede vascular hepática ${ }^{1-8}$.
O primeiro relato de segmentação hepática foi publicado por Hugo Rex em 1888, mas somente Couinaud sistematizou a segmentação do fígado com implicação nas hepatectomias. ${ }^{9,10}$

A maioria das descrições da segmentação hepática corresponde ao sistema venoso porta. Entretanto, a progressão das técnicas de abordagem

1. Cirurgião Geral do Instituto Dr. José Frota (IJF) e Mestrando em Cirurgia pela Faculdade de Medicina - UFC.

2. Acadêmico da Faculdade de Medicina - UFC; Bolsista PIBIC-CNPq.

3. Acadêmicos da Faculdade de Medicina - UFC.

4. Professor Titular do Departamento de Morfologia da Faculdade de Medicina - UFC; Mestre do Capítulo Ceará.

Recebido em : 27/12/2001

Aceito para publicação em : 10/12/2002

Resumo de Tese de Mestrado pelo Departamento de Cirurgia da Faculdade de Medicina da Universidade Federal do Ceará (UFC), realizada no Laboratório de Cirurgia Experimental (LABCEX). 
cirúrgicas do fígado tornou necessário o estudo da drenagem venosa hepática. Este trabalho objetiva verificar a drenagem venosa em fígados humanos, demonstrando sua segmentação independente e a relação entre seus segmentos.

\section{MÉTODO}

\section{Seleção e preparação do material anatômico}

Para a realização deste estudo foram utilizados trinta fígados humanos frescos oriundos do Departamento de Morfologia FM/UFC. Todos foram provenientes de cadáveres de ambos os sexos, sem alterações patológicas macroscópicas ou sinais de ruptura do parênquima hepático. Todos foram pesados e medidos os seus comprimentos, céfalo-caudal (CC), ântero-posterior (AP) e látero-lateral (LL).

As veias hepáticas, direita, média e esquerda, foram dissecadas e individualizadas em sua desembocadura na veia cava inferior.

\section{Injeção-Corrosão}

Foi injetada uma resina (Resapol T-208) com diferentes cores nas três veias hepáticas, de maneira seletiva, de modo que houvesse distinção entre os segmentos. À resina eram acrescidos o catalisador (peroxol), o monômero de estireno e o corante para formar uma mistura homogênea ${ }^{11}$.

Para isso, foi colocado um cateter de polietileno $\mathrm{n}^{\circ} 12$, fixado externamente com fio de algodão $\mathrm{n}^{\circ} 2$, em cada veia hepática. Foi realizada uma lavagem inicial com acetona a fim de desidratar o sistema ${ }^{3}$. Então, foram injetados de 20 a $30 \mathrm{ml}$ da mistura de resina em cada segmento, seletivamente, de maneira retrógrada, usando-se azul para veia hepática direita, vermelho para veia hepática média e amarelo para veia hepática esquerda.

Após a injeção da resina, os fígados foram colocados em solução de formol a 10\%, para fixação, por 24 horas. Em seguida, foram imersos em solução de ácido clorídrico a $30 \%$ até a completa corrosão da matéria orgânica.

Na etapa seguinte, os moldes foram lavados em água e detergente comum, por um dia, para retirada de detritos orgânicos ainda restantes e, posteriormente, colocados para secagem ao ar livre.

\section{Planimetria e Pesagem dos Moldes}

Os moldes foram fotografados horizontalmente através de um filme colorido, em suas faces diafragmática e visceral, para obtenção de suas áreas por contagem de pontos (planimetria) ${ }^{11}$. Somando o número de pontos das duas faces obtinha-se uma avaliação aproximada da proporção de área vascular que cada segmento representa no fígado. Os mesmos moldes foram pesados em balança de precisão de $0,5 \mathrm{~g}$, em totalidade e depois cada segmento venoso individualmente, aplicando-se a proporcionalidade dos segmentos de acordo com o peso dos moldes.

\section{Análise Estatística}

Para análise estatística dos dados foram utilizados o Teste de Friedman, para dados contínuos emparelhados, e a Correlação de Pearson, para associação entre duas variáveis.

Os dados serão expostos em média \pm desvio padrão.

\section{RESULTADOS}

O peso dos fígados estudados variou de 585 a $1360 \mathrm{~g}(\mathrm{M}=924 \pm 198)$.

Em todos os moldes de fígados, não foi observado mistura entre as cores injetadas isoladamente em cada veia hepática (Figura-1). Cada segmento venoso hepático tem uma drenagem independente.

O molde do segmento da veia hepática direita mostrou-se maior que os outros dois, quando se relaciona entre si os segmentos venosos dos moldes (Gráfico-1).

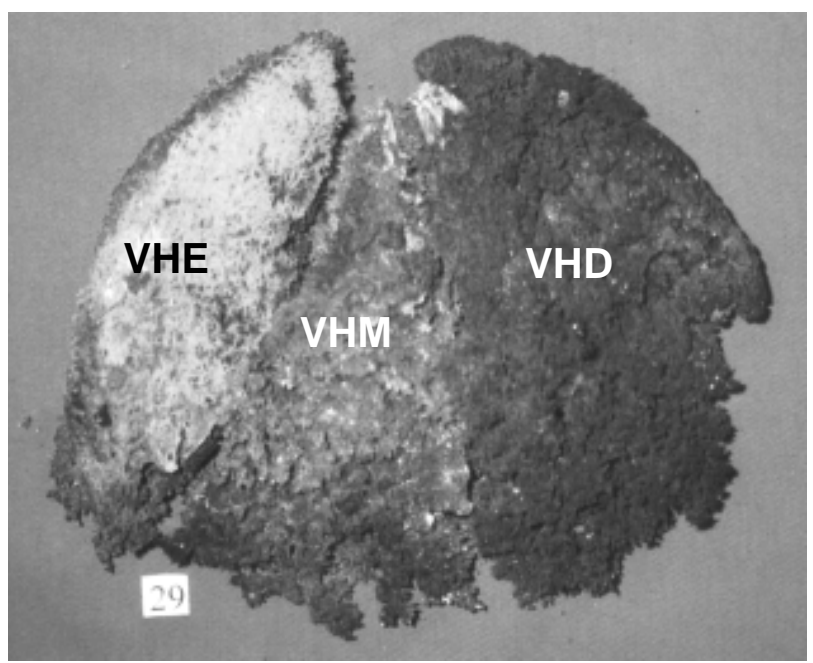

Figura 1 - Foto da face visceral do molde de resina do fígado obtido após a corrosão com ácido clorídrico a $30 \%$. VHD (veia hepática direita); VHM (veia hepática média); VHE (veia hepática esquerda). 
Grafico 1 - Comparação entre os volumes (pesos) dos segmentos venosos do fígado, direito, médio e esquerdo.

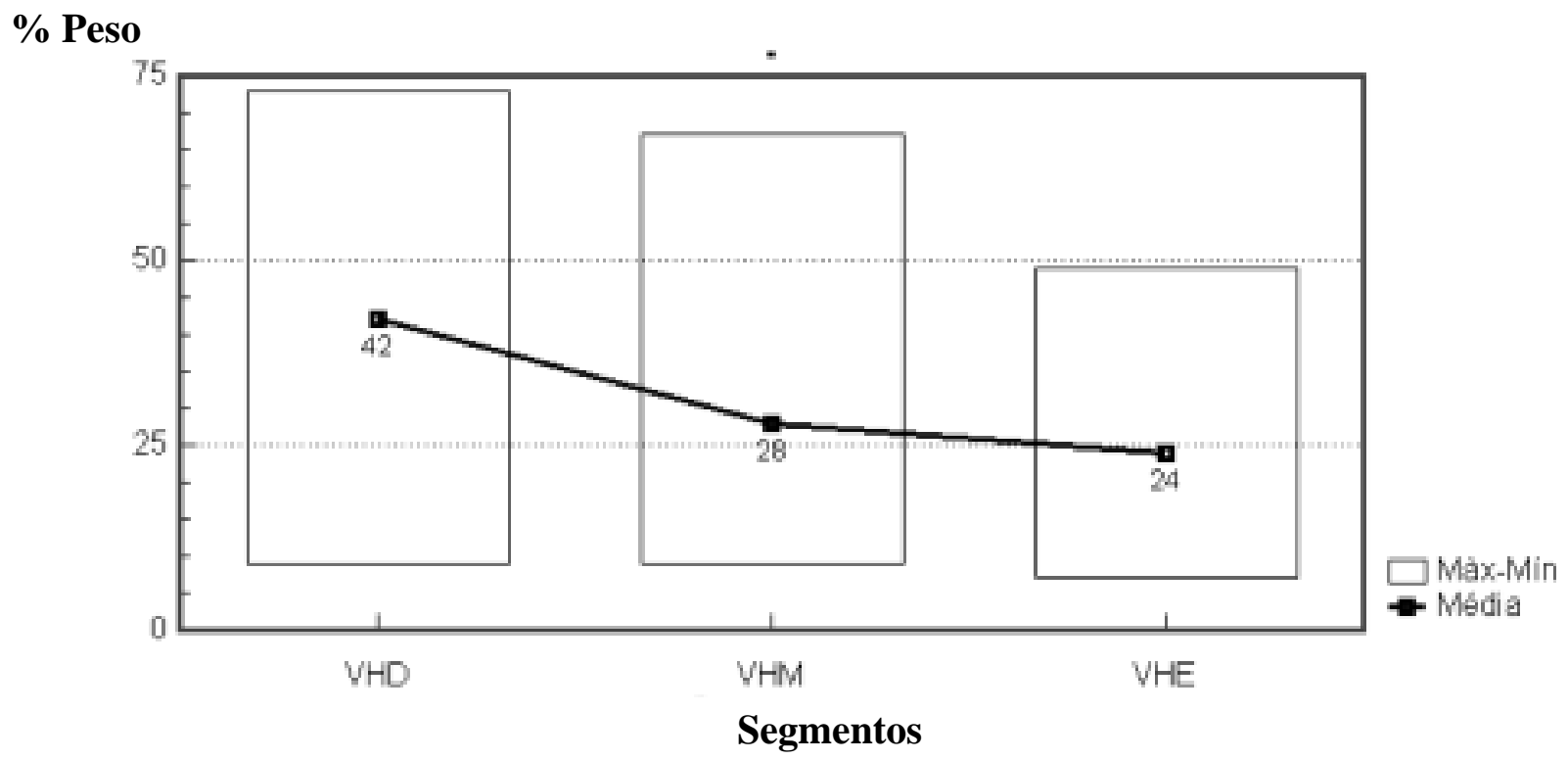

VHD (veia hepática direita); VHM (veia hepática média); VHE (veia hepática esquerda). * Qui-quadrado 10,6167 e p=0,005.

Quando foi comparado o aumento do peso do fígado com o aumento do peso dos moldes dos segmentos venosos, separadamente, não foi observado aumento desproporcional entre os segmentos, conforme exemplo do Gráfico-2.

\section{DISCUSSÃO}

Os moldes de drenagem venosa do fígado realizados com a resina de poliéster mostraram-se adequados e podem ser comparados aos com resina

Gráfico 2 - Relação entre o peso do fígado e a proporção do segmento direito no peso do molde

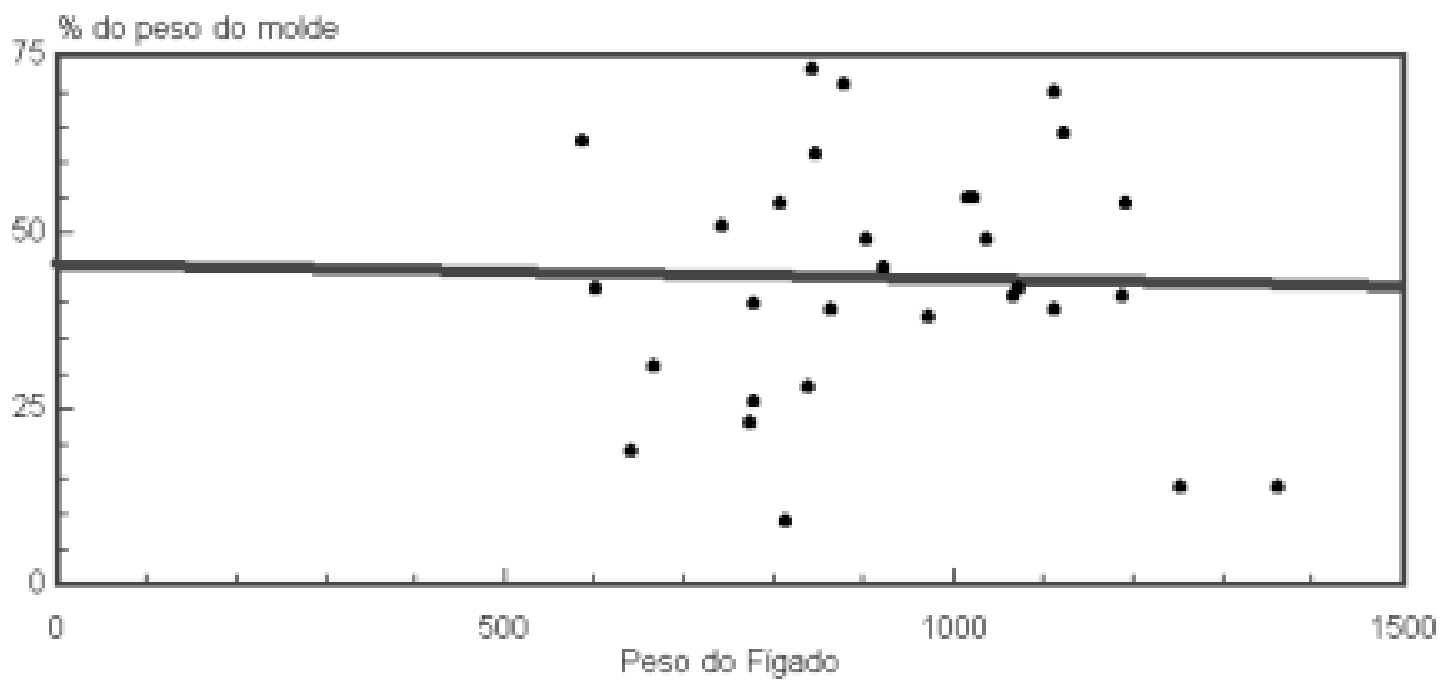

Coeficiente de correlação $=0,023$ 
de metilmetacrílico ${ }^{9}$, que são mais $\operatorname{caros}^{10}$ e de difícil obtenção. Como o endurecimento da resina de poliéster se faz pela adição de um catalisador, ocorre uma retração máxima de $2 \%$, resultando em um molde fiel e sem deformidades. A resina de poliéster (Resapol T-208) e o vinilite prestam-se ao estudo da segmentação e morfologia vascular, entretanto, somente o Resapol pode permitir o estudo das anastomoses inter-segmentares por seu poder de penetração capilar ${ }^{11}$.

A análise conjunta do estudo planimétrico e do peso dos segmentos venosos do fígado não revelou resultados semelhantes, conforme demonstra o Gráfico-3. Deste modo, não seria aplicável a utilização da planimetria neste trabalho, diferentemente de alguns relatos da literatura ${ }^{3}$. Isso deve-se, provavelmente, às maiores dimensões do fígado que os órgãos dos trabalhos observados, podendo causar maior erro de inferência estatística. Com isso, a proporção do peso entre os três segmentos venosos foi utilizado para o estudo, pois demonstra indiretamente o volume segmentar de cada veia hepática, conforme a fórmula volume $=$ peso $\mathrm{x}$ constante (coeficiente da resina).

Dada a independência dos segmentos das veias hepáticas, onde não foi observado mistura das cores injetadas seletivamente, pode-se sugerir que cada veia hepática drena um segmento hepático correspondente. Isso se aplica à hepatectomia parcial, importante conduta no transplante hepático e em patologias onde o fígado é acometido de maneira segmentar. O conhecimento da segmentação hepática acarretaria em menores complicações no pós-operatório, como o sangramento volumoso, por permitir uma abordagem mais precisa durante a ressecção cirúrgica. ${ }^{4,5}$

Quando foi comparado o peso do fígado e algum aumento desproporcional entre os seus segmentos venosos, não foi encontrado significância estatística (coeficiente de correlação $=0,023$ ). Desse modo, pode-se sugerir que, em fígados sem alterações patológicas, esses segmentos mantêm proporção entre si independente do peso do órgão.

Pela observação do Gráfico-1, verifica-se que o volume segmento direito da veia hepática é o maior proporcionalmente, mas não se pode afirmar, neste trabalho, qual o menor dentre o médio e o esquerdo.

Esses resultados estão de acordo, em parte, com os já apresentados por outros autores, que atribuem a maior drenagem à veia hepática direita ${ }^{12-14}$. Entretanto, estes autores não utilizaram nenhum método de quantificação dos segmentos para chegarem a estes resultados. No presente estudo, foi analisada esta proporcionalidade de maneira mais detalhada, por um método de quantificação (peso), de modo a apresentar resultados mais precisos.

Gráfico 3 - Comparação entre as proporções da planimetria e do peso de cada segmento venoso do molde.

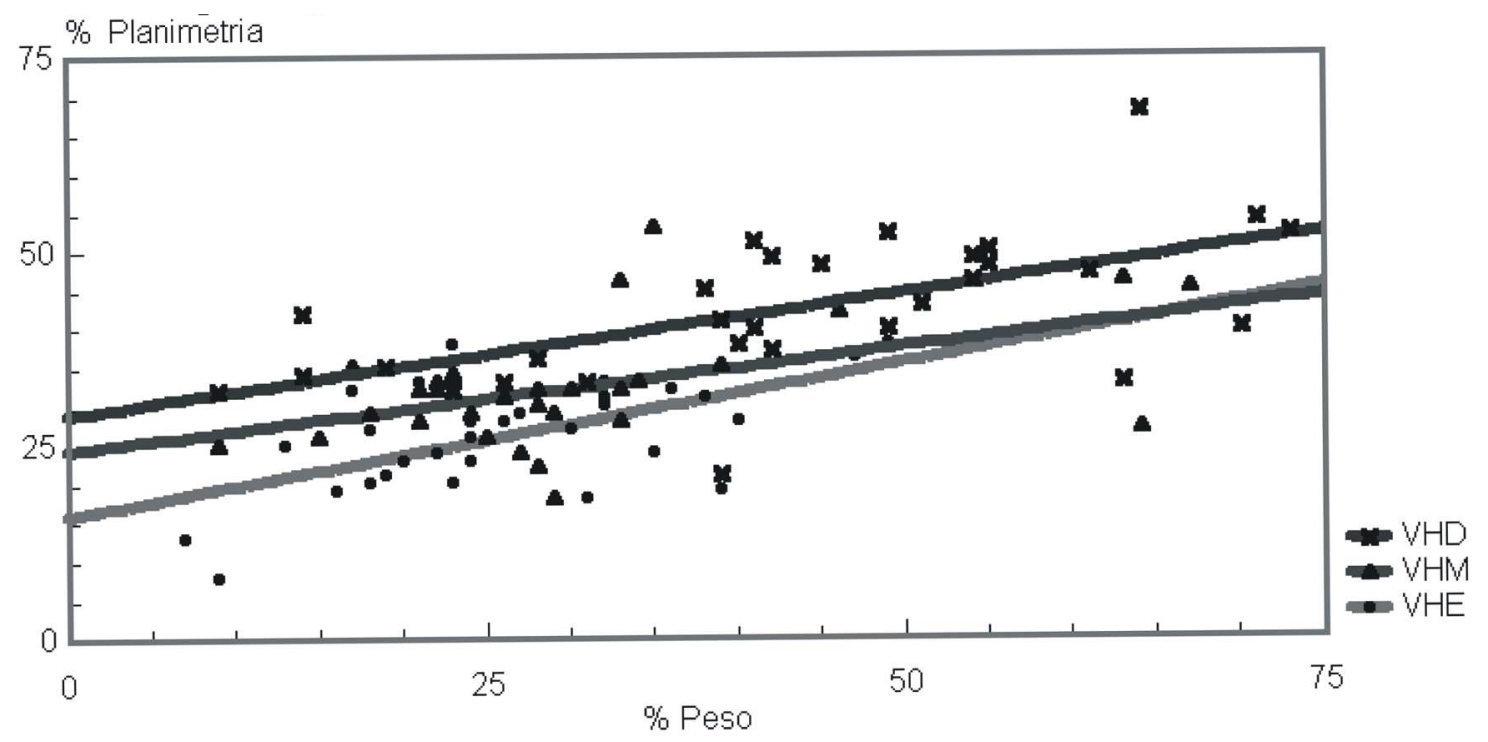

Regressão linear simples entre a proporção entre os segmentos na planimetria ou pesagem dos moldes. VHD (veia hepática direita); VHM (veia hepática média); VHE (veia hepática esquerda). Coeficiente de correlação 0,59; 0,58; 0,47 respectivamente. 
O estudo da drenagem venosa do fígado através da resina de poliéster, de vantagens relatadas, não permite conclusões definitivas. $\mathrm{O}$ avanço da tecnologia no campo da medicina, o advento de novas substâncias e os aparelhos de imagem, poderiam permitir uma pesquisa mais aprofundada do órgão.

O conhecimento da anatomia hepática, artérias, veias e ductos biliares, e a divisão do fígado em segmentos independentes são de grande importância na cirurgia de urgência e eletiva. $O$ transplante de fígado é um procedimento cada vez mais acessível para o ser humano em todo o mundo. O conhecimento da proporcionalidade e, principalmente, da independência intersegmentar entre os segmentos de drenagem venosa do fígado é de utilidade não só para o tratamento cirúrgico nas lesões traumáticas e nos tumores do fígado mas, principalmente, no transplante desse órgão.

\begin{abstract}
Objective: To establish the independence of segmentation of the hepatic venous drainage and the relationship among its segments. Methods: Thirty livers were carefully analyzed in order to exclude any intraparenchymatous injury. A synthetic resin (Resapol T-208) was injected into each one of the hepatic veins (right, middle and left), in different colors, to identify each segment, using the injection-corrosion technique. In each liver the obtained casts were weighed and submitted to planimetry, separately and altogether. Results: The fact that all the livers' casts have independent segments was noticed, and the right segment was the largest one $(p=0,005)$. A coefficient of 0,023 was obtained correlating the weight of the liver with the proportion of its segments. Conclusions: Hepatic venous segments are independent and the right venous segment is predominant. Furthermore, the weight of a healthy liver is proportional to the size of its segments.
\end{abstract}

Key words: Hepatic Veins; Corrosion casting; Liver.

\title{
REFERÊNCIAS
}

1. Freire E, Freire MA, Malvezzi A - "Trauma do Abdome”. In Trauma: a doença dos séculos. São Paulo: - Atheneu, 2001, pp. 1513-1536.

2. Chaib E, Antonio LG, Ishida R et al - Estudo do sistema venoso hepático e sua aplicação na técnica de transplante de fígado chamada "split-liver". Rev Hosp Clín Fac Med Univ São Paulo, 1995, 50(1): 49-51.

3. Bertalozzo W, Andreiuolo FM, Gazolla FM et al Territórios venosos do fígado em natimortos de termo. Estudo anátomo-cirúrgico e sua importância nas hepatectomias parciais regradas. Rev Bras Cir, 1994, 84 (2): 51-57.

4. Trivino $\mathrm{T}-$ Ressecções hepáticas menores segmentectomias - no tratamento das lesões focais do fígado: técnicas e resultados. Dissertação (Doutorado). São Paulo. Universidade de São Paulo, 2001, 169 p.
5. Ribeiro Filho J, Vieira OM, Hannoun L, et al. Hepatectomias. Rev Col Bras Cir, 1992, 19(5):230-236.

6. Kanemura E, Togo S, Shizawa R, et al - Subdivision of liver anterior segment into two units according to hepatic venous drainage. Hepatogastroenterology, 2000, 47(34): 1056-1059.

7. Sharma D, Deshmukh A, Raina VK. - Surgical anatomy of retrohepatic inferior vena cava and hepatic veins: a quantitative assessment. Indian J Gastroenterol, 2001, 20(4): 136-139.

8. Kogure K, Kuwano H, Fujimaki N, et al - Relation among portal segmentation, proper hepatic vein, and external notch of the caudate lobe in the human liver. Ann Surg, 2000, 231(2): 223-228.

9. Ribeiro Jr MA, Goldenberg S, Prates JC. - Estudo da anatomia vascular sanguínea e biliar do segmento lateral esquerdo do fígado e sua aplicação cirúrgica. Acta Cir Bras, 13(1): 30-36. 
10. Silva VA, Miranda JS, Brito MVH. Técnica para preparo angioarquitetônico hepático de ratos. Acta Cir Bras, 2000, 15(3): 177-181.

11. Silva AR - Vascularização arterial do baço: estudo da independência e análise proporcional dos seus segmentos. Dissertação (Doutorado em Anatomia). São Paulo. Universidade de São Paulo. 1991, 62 p.

1. 12. Hata F, Murakami G, Hirata $\mathrm{K}$ et al - Configuration of hepatic veins in the right surgical lobe of the human liver with special reference to their complementary territorial relationships: morphometric analysis of controlled specimens with clearly defined portal segmentation. Okajimas Folia Anat Jpn, 1999,76(1): 1-16.
13. Soyer P, Heath D, Bluemke DA, et al - Three-dimensional helical CT of intrahepatic venous structures: comparison of three rendering techniques. J Comput Assist Tomogr, 1996, 20(1): 122-127.

14. Guerrini RM, Cerri GG, Magalhães A - Critérios para segmentação hepática. Rev Imagem, 1988, 10(3): 107110.

Endereço para correspondência:

Dr. Fernando César Diógenes Filho

Av Heráclito Graça 653, Centro

60140-061 - Fortaleza - Ceará

E-mail: fdiogenes@secrel.com.br 